\title{
MEDIÇÃO DO GRAU DE INOVAÇÃO COM ÊNFASE NA DIMENSÃO PROCESSO PARA PEQUENAS INDÚSTRIAS DA REGIÃO SUL DE SÃO PAULO
}

\author{
Adriano Gomes de Freitas (adriano.gomes@ufabc.edu.br) - Programa de Pós-Graduação em \\ Engenharia e Inovação - Universidade Federal do ABC \\ Alexandre Caramelo Pinto (alexandre.pinto@ufabc.edu.br) - Programa de Pós-Graduação em \\ Engenharia e Inovação - Universidade Federal do ABC
}

Júlio Francisco Blumetti Facó (julio.faco@ufabc.edu.br) - Programa de Pós-Graduação em Engenharia e Inovação - Universidade Federal do ABC

Alexandre Acácio de Andrade (aacacio@ufabc.edu.br) - Programa de Pós-Graduação em Engenharia e Inovação - Universidade Federal do ABC

Vinicius Tasca Faria (vinicius.tasca@ufabc.edu.br) - Programa de Pós-Graduação em Engenharia e Inovação - Universidade Federal do ABC

Felipe Heidrich (felipe.heidrich@ufabc.edu.br) - Programa de Pós-Graduação em Engenharia e Inovação - Universidade Federal do ABC

\begin{abstract}
RESUMO
No contexto brasileiro das micro e pequenas empresas (MPE), que representam mais de $93 \%$ do total de empresas ativas no país (SEBRAE, 2017), a perspectiva de que o papel da inovação em processos deve receber uma atenção especial nos remete à escrita deste artigo, com o objetivo de mensurar as dimensões da inovação nos empreendimentos na atualidade. Foi utilizado como apoio, o modelo de ferramenta de metodologia de diagnóstico, já consagrado para realização da análise de dados junto às necessidades de cada organização. E por meio desta metodologia baseada nas 12 dimensões da inovação descritas por Mohanbir Sawhney (2006) e adaptado por Bachmann \& Destefani (2008), utiliza-se uma amostra de 20 MPE do segmento industrial para o trabalho de campo da pesquisa in loco na região sul de São Paulo. Derivado do intuito de promover e colaborar com sugestões, a fim de melhorar as oportunidades de serem replicadas a outras organizações que possuem desafios similares. O enfoque das contribuições deste trabalho se fez em relação à dimensão "processos", uma vez que, a maioria dos participantes obtiveram resultados em comum, unido à necessidade de se diferenciarem de seus concorrentes. Finalmente, verifica-se as tendências de negócios junto às demandas dos temas atuais.
\end{abstract}

Palavras-chave: MPE; inovação; indústria; processos; mensuração da inovação.

Área: Inovação e a gestão do desenvolvimento de produtos e serviços em empresas no Brasil.

\section{INTRODUÇÃO}

Nos anos 80, a indústria atingiu seu pico em $22 \%$ do valor adicionado a economia brasileira. Entretanto, essa trajetória entrou em declínio acelerado na década passada e, ao final de 2014, o PIB nacional proveniente desse segmento foi estimado em 10,8\%, segundo dados do IBGE (2017). Após, a crise econômica fez da indústria sua grande vítima, totalizando uma queda de $6,2 \%$, entre janeiro de 2015 a dezembro de 2016, a maior baixa da história, de acordo com o Instituto. Atualmente, o cenário econômico continua desfavorável, o que induz as empresas optarem por uma linha de produção enxuta e com custos reduzidos, segundo o SEBRAE (2017).

Mesmo com drásticas quedas em faturamento, a indústria nacional ainda representa o segundo maior parque industrial da América (IBGE, 2017), que variam desde os setores siderúrgico, 
automotivo, aéreo, informática e até de bens de consumo duráveis. Em meio a um cenário incerto de urgência e de risco, faz-se necessário inovar para a geração de valor econômico a longo prazo, tornando-se algo fundamental para a sobrevivência das empresas ao competitivo mercado atual.

No universo das micro e pequenas empresas (MPE), para possuir um bom controle orçamentário, inovar é um desafio, pois, segundo o Manual de Oslo, produzido pela Organização para Cooperação e Desenvolvimento Econômico:

A inovação compreende várias atividades que não se inserem em $\mathrm{P} \& \mathrm{D}$, como as últimas fases do desenvolvimento para pré-produção, produção e distribuição, desenvolvimento com um grau menor de novidade, atividades de suporte como treinamento e preparação de mercado, e atividades de desenvolvimento e implantação para inovações tais como novos métodos organizacionais de produto e de processo. As atividades de inovação podem também incluir a aquisição de conhecimentos externos ou bens de capital que não são parte da P\&D (OCDE, 2007, p. 25).

Conforme o enfoque neo-schumpeteriano, a inovação é imprescindível para sobrevivência de uma firma, principalmente em mercados de elevada concorrência. Com as dificuldades econômicas inerentes à atual crise econômica brasileira, as condições para gerar uma cultura de inovação tornam-se difíceis para as pequenas indústrias (SEBRAE, 2017).

Este trabalho estudou e aplicou uma ferramenta de diagnóstico para mensurar o grau de inovação nas MPE, a fim de contribuir e disseminar a cultura da inovação como uma alternativa para mitigação dos efeitos da crise.

O objetivo geral deste artigo é compreender as influências referentes à melhoria e inovações na dimensão "processos", quanto afeta o grau de inovação das empresas da amostra e entender como estudos de casos, presentes na literatura, contemplaram o tema até o presente. O objetivo específico é diagnosticar e contribuir com sugestões de inovações em processos de vinte pequenas empresas do segmento industrial da zona sul da capital de São Paulo.

\section{INOVAÇÃO}

De acordo com o Manual de Oslo (OCDE, 2007), o requisito mínimo para se definir uma inovação é que o produto, processo, método de marketing ou organizacional de uma empresa sejam novos ou significativamente melhorados. Isso inclui produtos, processos e métodos, os quais as empresas são as pioneiras a desenvolver, bem como aqueles que foram adotados de outras organizações, mas que são novos para a empresa que os adotou (p. 37).

Segundo Facó e Mandel (2016) a inovação se difere da invenção, já que:

A invenção surge de um processo criativo, sem necessariamente um objetivo comercial definido previamente. A partir do momento em que um novo produto, serviço, negócio ou processo chega à sociedade e produz algum resultado, aí sim se torna inovação (FACÓ; MANDEL, 2016, p. 14).

No Manual de Oslo, a inovação visa melhorar o desempenho de uma organização através do aprimoramento de sua vantagem competitiva, ou ainda, pela manutenção de sua competitividade. Dessa forma, pode ocorrer por meio de desenvolvimento e melhorias no mix de produtos ou conquista de novos mercados/clientes. Alternativamente, podem ocorrer pela via da redução de custos unitários de produção, compras, distribuição ou transação. Ou ainda, optar pelo aprimoramento da sua capacidade inovativa, aumentando sua habilidade para desenvolver produtos e processos para adquirir e criar conhecimento (OCDE, 2007).

Observando individualmente cada organização, percebe-se um sistema customizado, com seus atributos e características específicas para suas próprias necessidades. Assim, as inovações 
empreendidas devem reforçar esses diferenciais, buscando eficiências compatíveis com o ambiente em que está inserida, seus produtos e clientes, objetivando melhores resultados a curto prazo, geralmente de natureza tangível, e desejavelmente intangíveis, mais perceptíveis a médio e longo prazo.

Sob a perspectiva empreendida neste estudo, a dimensão "processo" assume uma relevância ainda mais interessante no universo das MPE, visto que a inovação pode se fazer presente tanto nos processos que envolvem uma área específica do negócio - como vendas, contas a pagar, etc.-, e, portanto, mais simples de serem implementadas, quanto nos processos interfuncionais ou interorganizacionais que conectam diferentes áreas do negócio, clientes e fornecedores, ao longo da cadeia de valor. Cabe frisar que, frequentemente, estes últimos, requerem um esforço muito maior em termos de conhecimento e tecnologias da informação e comunicação ou TICs (DAVENPORT, 1990). Os pequenos empresários podem dar seus primeiros passos em busca de uma melhor competitividade através de seus esforços de caráter incremental e de resultados mais imediatos, pois, grande parte de sua competitividade é derivada da forma como a organização articula seus processos empregando tempo, pessoas e espaço, que, nas visões de Joia (1994) e Turban, Wetherbe e Mclean (2004), aparecem refletidas conforme abaixo:

Figura 1. Representação gráfica de um processo (workflow)

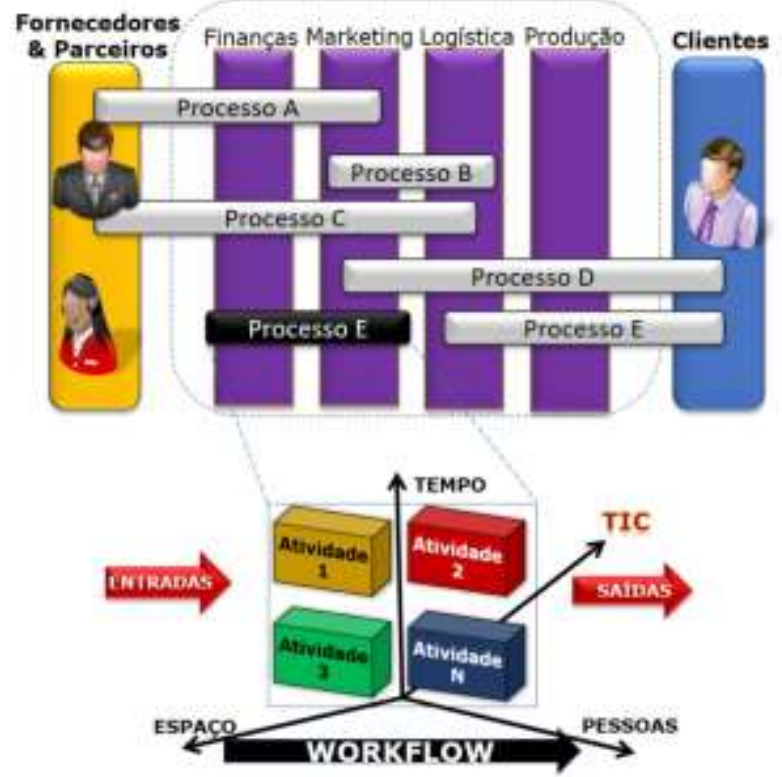

Fonte: Adaptação dos autores baseada em Joia (1994) e Turban, Wetherbe e Mclean. (2004)

A aplicação eficaz das TICs, conforme retratado na imagem acima, como veículo da inovação ainda que não seja trivial, tende a permitir que haja uma redução perceptível nos três eixos refletida em benefícios, que podem se traduzir em ganhos de produtividade e custos em benefício da organização. Segundo estes autores, a aplicação se deve a um:

(...) conjunto de atividades interligadas entre si, dependentes do tempo, de pessoas e espaço, que recebendo inputs (dados) devem gerar outcomes (resultados) de valor agregado, seja para o cliente interno ou externo (JOIA, 1994, p. 20).

\section{METODOLOGIA: RADAR DA INOVAÇÃO}

O Radar da Inovação empregado neste trabalho, foi criado por Sawhney, Wolcorr e Arroniz da Kellogg School of Management (2006), posteriormente adaptado por Bachmann \& Associados (2008), e avalia por meio de um questionário o momento de uma MPE em relação à inovação. A escolha da ferramenta se deu por conta do enfoque que se mensura o grau de maturidade no uso do processo de inovação em empresas de pequeno porte através de suas 
características que se diferenciam das médias e grandes empresas. Observado o contexto das MPE, seria inadequado considerar aspectos como número de patentes e investimentos em pesquisa e desenvolvimento (P\&D) para mensurar inovação, como é utilizado no Manual de Oslo, uma vez que este não distingue o porte das organizações.

De acordo com Bachmann (2008), a inovação das MPE ocorre de formas diferentes das grandes empresas, e, portanto, a forma de mensurar o grau de inovação deve ser distinta. Diversos estudos concluem que o processo de gestão da inovação conta com uma dimensão física, com estruturas organizacionais favoráveis e uma dimensão intangível, relacionada à comportamentos, liberdade de comunicação, cultura de aceitação de riscos e à prática de técnicas de criatividade. $\mathrm{O}$ modelo adotado além da mensuração, visa a implementação de melhorias com planos de ações em conjunto com o acompanhamento de um aprendizado contínuo e personalizado a cada empresa.

O mapeamento e o agendamento das visitas às MPE, seguido de uma sensibilização dos empresários com perfil condizente para o estudo, foi realizado dentro do seguinte pressuposto: empresas de pequeno porte (EPP) enquadradas pelo faturamento anual de R $\$ 360$ mil até 3,6 milhões por ano, do segmento industrial, da região sul de São Paulo. A noção de que fatores regionais podem influenciar a capacidade inovadora das empresas levou a um interesse crescente na análise da inovação no âmbito regional (OCDE, 2007).

Diante disso, realizou-se in loco a aplicação do questionário de diagnóstico, denominado Radar da Inovação, onde os dados coletados são analisados ao longo deste artigo:

\begin{abstract}
A ferramenta Radar da Inovação dispõe de uma análise que compreende treze dimensões: oferta, plataforma, marca, clientes, soluções, relacionamento, agregação de valor, processos, organização, cadeia de fornecimento, presença, rede e ambiência inovadora da organização, segundo a análise do grau de inovação em cada setor e classificação das empresas em pouco ou nada inovadoras, inovadoras ocasionais ou inovadoras sistêmicas (BACHMANN et al, 2011, p. 23).
\end{abstract}

"O Radar da Inovação avalia quanto o ambiente de um negócio é propício à inovação, afinal, o conceito amplamente aceito é que uma empresa inovadora é o local onde as pessoas estão capacitadas a resolver problemas e onde a criatividade é parte da cultura organizacional" (Bachmann et al, 2011, p. 68). Logo, a mensuração com o Radar da Inovação não é absoluta, mas uma referência sobre as oportunidades de melhoria e o potencial de inovar, existentes na organização analisada.

Comparado ao artigo inicial de Sawhney (2006), Bachmann institui sua perspectiva sob uma nova dimensão à parte das doze existentes: a dimensão ambiência inovadora agregada diretamente aos serviços de influenciadores como provedor externo de inovação, consultorias, agências de fomento, assessoria, universidades, centros de pesquisa e etc. Dessa forma, no questionário produzido para gerar o radar, cada questão adota uma escala Likert com três níveis e pontuações, que vai de 1 a 5 , a fim de identificar e classificar as empresas quantitativamente. $\mathrm{O}$ primeiro nível é o de empresas pouco ou nada inovadoras, correspondente à pontuação 1; o segundo nível é o de empresas inovadoras ocasionais, sendo a pontuação correspondente, 3 ; e o terceiro nível é o de empresas inovadoras sistêmicas, com pontuação correspondente igual a 5 (BACHMANN et al, 2008). O lapso temporal considerado foi relativo aos três últimos anos, medindo, dessa forma, o momento atual da organização, já que ações tomadas anteriormente a esse período não se enquadram nos critérios da atualidade mencionados.

O questionário do Radar da Inovação é feito em entrevistas formais in loco, podendo ocorrer de forma individualizada ou em grupo dos responsáveis pelas decisões na organização participante. Após a aplicação dessa ferramenta, os dados são tabulados a fim de gerar tabelas 
e gráficos que permitem visualizar e analisar o grau de inovação de cada uma das treze dimensões do radar, resultando no índice global de inovação da organização.

Tabela 1. Tabela gerada pelo Radar da Inovação para uma determinada organização

\begin{tabular}{|l|l|}
\hline Grau de inovação & Média \\
\hline A-Oferta & 4.0 \\
\hline B - Plataforma & 4.5 \\
\hline C-Marca & 3.0 \\
\hline D-Clientes & 2.5 \\
\hline E- Soluções & 3.1 \\
\hline F-Relacionamento & 4.0 \\
\hline G-Agregação de valor & 3.1 \\
\hline H - Processos & 1.0 \\
\hline I- Organização & 2.5 \\
\hline J-Cadeia de fornecedores & 3.1 \\
\hline K-Presença & 2.0 \\
\hline L-Rede & 2.0 \\
\hline M-Ambiéncia inovadora & 2.0 \\
\hline Grau de inovação Global & $\mathbf{3 . 7}$ \\
\hline
\end{tabular}

Fonte: Elaboração pelos autores

Os resultados foram posteriormente apresentados como devolutiva em forma de feedback para os responsáveis de cada organização, no qual se explica com maiores detalhes os pontos de maior relevância de maneira personalizada a cada empresa. A Tabela 1, exemplifica o modelo de tabela para cada empresa e, a Figura 2, o modelo do gráfico gerado pelo questionário. Observando-se o gráfico abaixo, percebe-se que as extremidades correspondem às dimensões que obtiveram maior pontuação na empresa. Em contrapartida, os pontos mais próximos do centro do gráfico correspondem às dimensões menos desenvolvidas, sendo estas, oportunidades de melhoria, sendo sempre, decisão dos empresários em quais dimensões estão dispostos a trabalhar e de acordo com o impacto que causarão.

Figura 2. Gráfico gerado pelo Radar da Inovação para uma determinada empresa

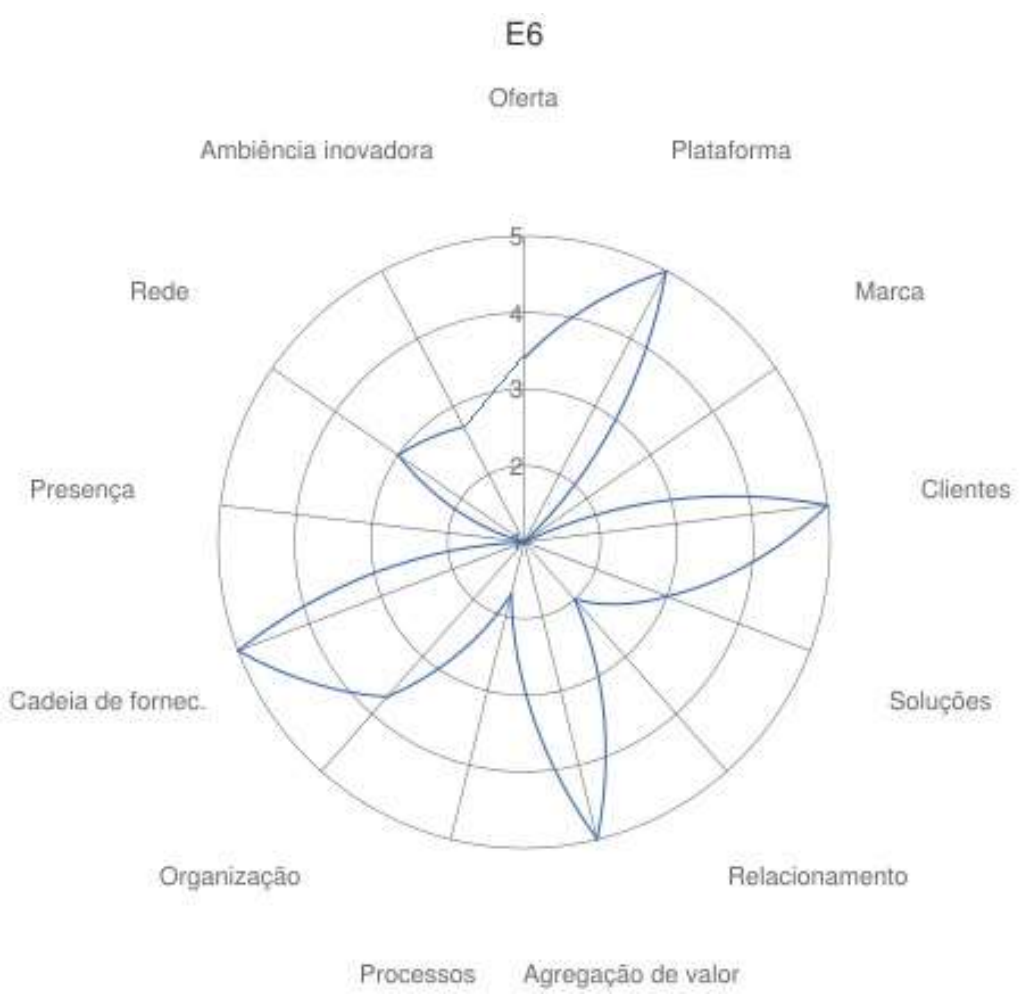

Fonte: Elaboração pelos autores 
Observando as médias obtidas do conjunto de 20 empresas da amostra, identifica-se que a dimensão com menor índice é a de "processo" (correspondente à letra $\mathrm{H}$ na tabela 1). Portanto, incipientemente explorada, revela-se como oportunidade potencial de inovação dentro das organizações. Analisou-se também que correspondente à realidade da crise econômica, essa dimensão tem relevância para o segmento no âmbito da inovação das pequenas indústrias, uma vez que a redução dos volumes de produção é, em muitos casos, uma alternativa de redução de custos operacionais pela via da diminuição do efetivo. Assim, limita-se a linha de produção ao mínimo, ocasionando um clima menos propenso à inovação devido à insegurança do desemprego. Dos casos observados na amostra, uma indústria gráfica perdeu um cliente que demandava $60 \%$ de sua produção, resultando em cortes de funcionários com salários melhores porém mais qualificados, por falta de mão de obra especializada que dominavam certas técnicas de acabamento, gerou problemas e retrabalhos em seus processos e prejuízos que, a priori, se buscava eliminar. Outro aspecto notado na crise foi a eliminação de serviços externos, como os de consultorias ou de treinamentos.

\section{ANÁLISE E DISCUSSÃO DOS RESULTADOS}

Durante a pesquisa, notou-se que os empresários consideram difícil a captação de recursos a longo prazo ou a taxas razoáveis para financiar a inovação, levando-os a perseguirem inovações por necessidade e, portanto, de forma reativa, não por oportunidade. Ao analisar todas as organizações da amostra, foi possível diagnosticar e definir oportunidades de melhoria nos Processos:

a) Gestão de Pessoas: os empresários, em sua maioria, apontaram nos questionários insatisfação com os colaboradores relativo aos relacionamentos e à cultura da empresa, por exemplo, citações diretas de comportamento, assiduidade, delegação de tarefas e comprometimento com as regras da organização;

b) Gestão Financeira: devido ao desenvolvimento ou má utilização de fluxos de caixas, administração de contas a pagar e receber com inexistência de planejamento e de educação financeira;

c) Gestão de Marketing: deficiências para agrupar clientes de acordo com suas necessidades, fidelização, prospecção de clientes, divulgação e pós-vendas;

d) Gestão Organizacional: definição de cargos e tarefas, delegação de funções e identificação de responsáveis para cada atividade;

e) Planejamento e Controle de Processos de Produção: nos casos mais graves, foi constatado inexistência de acompanhamento ou alinhamento entre estoque, produção, controle de qualidade, expedição e planejamento que fossem superior a um dia.

Conforme os obstáculos de gestão de processos priorizaram-se, inicialmente, contribuições para gerar uma base comum de trabalho para as empresas, com desenvolvimento de planos de ações em busca da resolução dos agravantes e com ações voltadas aos processos de gestão empresarial. Essa premissa evidencia a afirmação de que uma gestão alinhada e consolidada é o primeiro passo para iniciar a cultura de inovação de maneira contínua em busca de resultados significativos e de longo prazo (PORTER, 2001).

Foi observada também, durante o período de pesquisa nas organizações, uma redução significativa no quadro de funcionários de todas aquelas que perderam clientes ou tiveram aumento de gastos, o que dificultou ainda mais a participação de seus empresários nas realizações das ações de inovação em seus processos. Além disso, existem diversos outros motivos, como o descaso, a falta de monitoramento, inexistência de metodologia ou disciplina 
para a manutenção dos processos da organização, almoxarifados, setor fabril e escritórios. Identificaram-se desperdícios que deveriam ser evitados se analisados de maneira estratégica.

Ampliando o foco, alguns fatos agravaram a gestão organizacional e a reestruturação das pequenas empresas da amostra, segundo o SEBRAE (2017), a principal causa da queda do crescimento da produção da indústria manufatureira foi a redução dos investimentos, especialmente em máquinas e equipamentos, tanto de empresas privadas quanto das estatais. Outra dificuldade identificada foi encontrar mão de obra qualificada ou alcançar novos mercados de atuação, que evidencia deficiências nas estratégias ou dos investimentos, limitando o uso da capacidade produtiva e gerando capacidade ociosa. A Tabela 2 dispõe as pontuações atingidas a cada dimensão. As organizações estão identificadas com a letra "E" na parte de cima da tabela, assim como as médias por dimensão, na coluna da extremidade direita e por empresa, última linha da tabela:

Tabela 2 - Pontuação obtidas do Radar da Inovação aplicado nas empresas da amostra

\begin{tabular}{|c|c|c|c|c|c|c|c|c|c|c|c|c|c|c|c|c|c|c|c|c|c|}
\hline Dimensão & El & E2 & E3 & E4 & E5 & E6 & E7 & E8 & E9 & El0 & Ell & El2 & El3 & El4 & E15 & E16 & El7 & E18 & E19 & E20 & MEda \\
\hline Oferta & 3,0 & 4,0 & 4,0 & 3,0 & 3,0 & 4,0 & 4,0 & 4,0 & 4,0 & 2,0 & 3,0 & 3,1 & 5,0 & 4,0 & 4,0 & 4,0 & 5,0 & 4,0 & 4,0 & 4,0 & 3,8 \\
\hline Plataforma & 2,0 & 1,0 & 5,0 & 4,0 & 4,0 & 3,0 & 2,0 & 1,0 & 4,0 & 2,0 & 3,0 & 4,0 & 2,0 & 2,0 & 3,0 & 2,0 & 4,0 & 2,0 & 4,0 & 4,0 & 2,9 \\
\hline Marca & 3,0 & 3,0 & 4,0 & 2,0 & 3,0 & 3.0 & 3,0 & 3,0 & 20 & 3,0 & 1,0 & 3,0 & 4,0 & 20 & 4,0 & 3,0 & 2,0 & 4,0 & 4,0 & 3,0 & 2,9 \\
\hline Cientes & 1,7 & 1,3 & 4,3 & 3,1 & 2,0 & 2,7 & 3,7 & 2,3 & 2,3 & 3,7 & 2,0 & 2,0 & 3,0 & 2,0 & 3,0 & 3,7 & 2,0 & 3,0 & 3,0 & 3,0 & 2,7 \\
\hline Soluções & 1,0 & 3,0 & 5,0 & 2,0 & 3,0 & 3,0 & 3,0 & 4,0 & 20 & 3,0 & 4.0 & 4,0 & 2,0 & 2,0 & 3,0 & 3,0 & 4,0 & 3.0 & 4,0 & 4,0 & 3,1 \\
\hline Relacionamento & 2,0 & 2,0 & 4,0 & 4,0 & 1,0 & 4,0 & 5.0 & 1,0 & 4,0 & 4,0 & 4.0 & 4,0 & 2,0 & 20 & 3,0 & 5,0 & 3,0 & 4.0 & 4,0 & 4,0 & 3,1 \\
\hline Agregação de valor & 1,0 & 1,0 & 2,0 & 2.0 & 2,0 & 3,0 & 3,0 & 4,0 & 20 & 20 & 2,0 & 2,0 & 2,0 & 20 & 3,0 & 3,0 & 3,0 & 3.0 & 3,0 & 20 & 2,3 \\
\hline Processos & 1,0 & 1,0 & 1,0 & 2.0 & 1,0 & 2,0 & 1,0 & 2,0 & 2,0 & 1,0 & 2,0 & 2,0 & 2,0 & 2,0 & 3,0 & 2,7 & 2,0 & 2.3 & 2,3 & 3,0 & 1,8 \\
\hline Organização & 3,7 & 2,0 & 3,1 & 1.7 & 3,0 & 4,0 & 3,7 & 3,7 & 2,3 & 2,0 & 4,2 & 2,0 & 3,0 & 2,0 & 3,0 & 3,7 & 3,0 & 3.0 & 2,0 & 3,0 & 3,0 \\
\hline Cadeia de fomecedores & 1,3 & 2,0 & 2,0 & 3,1 & 4,0 & 4,0 & 2,0 & 2,0 & 2,0 & 2,0 & 4,0 & 2,0 & 2,7 & 1,0 & 3,0 & 2,0 & 2,0 & 1.0 & 3,0 & 4,0 & 2,5 \\
\hline Presença & 2,0 & 1,3 & 3,1 & 3,0 & 2,0 & 4,0 & 2,0 & 1,7 & 2,0 & 2,7 & 2,3 & 3,0 & 3,0 & 3,0 & 4,0 & 2,0 & 2,0 & 3,0 & 3,0 & 2,0 & 2,6 \\
\hline Rede & 2,0 & 1,7 & 2,1 & 4,0 & 2,0 & 3,0 & 4,0 & 2,0 & 2,0 & 3,0 & 2,0 & 4,0 & 2,0 & 2,0 & 4,0 & 4,0 & 3,0 & 3,0 & 4,0 & 2,0 & 2,8 \\
\hline Ambiência movadora & 1,3 & 2,0 & 2,0 & 2,7 & 2,1 & 2,7 & 2,0 & 2,0 & 1,3 & 20 & 2,0 & 2,0 & 2,3 & 1,0 & 2,7 & 2,0 & 1,9 & 2,0 & 3.3 & 3,3 & 2,1 \\
\hline Média da empresa & 1,92 & 1,95 & 3,2 & 3,09 & 2,47 & 3,28 & 2,78 & 2,52 & 2,45 & 2,49 & 2,5 & 2,85 & 2,69 & 2,08 & 3,28 & 3,08 & 2,84 & 3 & 3,36 & 3,18 & 2,73 \\
\hline
\end{tabular}

Fonte: Elaboração pelos autores

Oito empresas alcançaram média acima de 3 e são consideradas pela metodologia, empresas inovadoras ocasionais, porém, a maioria delas responderam não ter obtido mudanças significativas em seus processos nos últimos três anos, o que resultou em pontuações baixas na dimensão "processo", recebendo o grau pouco ou nada inovadoras. Tal fato demonstra que, sob a perspectiva desses gestores, seus processos não têm obtido o foco de inovação desejável. Identificado que $60 \%$ das organizações estão com média abaixo de 3 , a maioria atingiu uma pontuação mínima na dimensão "processo". O fator comum nas empresas foi a conduta dos empresários, que tratam inovação como algo pontual e não como um processo contínuo. Das vinte organizações pesquisadas, sete foram ranqueadas abaixo da metade, que as posicionam como organizações pouco inovadoras em sua média global, e, por fim, consideradas inovadoras sistêmicas apenas com uma pontuação de 5 (máximo do desempenho global de inovação). Calculando-se a médias dos pontos obtidos em gestão organizacional na amostra, o resultado alcançado foi a pontuação acima da média, o que evidencia que cada empresa é um universo diferente e enfrentam desafios distintos, mesmo pertencendo ao mesmo porte industrial.

Após o diagnóstico, de maneira individualizada, entende-se que a principal solução para os problemas identificados, foi a sugestão de ações às empresas, ao buscarem melhorias em gestão e, assim, construir uma base para o desenvolvimento da cultura de inovação dos seus processos de trabalho. Constatou-se que a maioria das organizações realizaram inovações "emergenciais", ou seja, aquelas decorrentes da falta de alternativas que visavam sua sobrevivência no mercado. As dimensões que mais apresentam atividades em desenvolvimento inovativo, com maiores pontuações, nas amostras são: Presença, Oferta, Marca e Relacionamento. 
As ações mais implementadas para melhoria nos processos foram: realização de cursos de gestão de pessoas; de qualidade e financeiros; consultorias e assessorias para implantação ou melhor uso de fluxo de caixa; organograma organizacional; oficina de marketing digital e físico; padronização dos processos e do atendimento aos clientes a fim de reduzir o desperdício; otimização de recursos e aumento da satisfação dos clientes; implantação de programa de fidelização e realização de cadastro dos clientes; ampliação do público-alvo com atendimento a novos mercados, participação de feiras, congressos; e, por fim, oferecimento de novos produtos ou kits montados com os produtos existentes.

Observando a Tabela 2, nota-se que a maioria das organizações obtiveram escore 1 na dimensão "processo", significando que, ultimamente, não inovaram ou inovam pouco. A experiência em campo mostrou que os empresários, em sua maioria, são conservadores em relação à produção, demonstrando certo receio de investir nessa dimensão, pois, acarretaria períodos de adaptação da equipe ou de maturação do processo. Por não disporem de capital de investimento, procuram trabalhar outras dimensões que possam ter retorno a curto prazo, como redução de custos ou foco nas vendas diretas.

Observado que, embora essas empresas sejam enquadradas pelo seu faturamento como empresas de pequeno porte, sua gestão mostrou-se mais próxima do perfil de microempresa, com operações administrativas deficientes, nas quais, os empresários estão voltados para as atividades produtivas ou de rotina, com dificuldades para manter colaboradores capacitados. Resultando em, gargalos de produção e falta de incentivo à inovação.

A grande dificuldade percebida pelos gestores das empresas foi a delegação das tarefas rotineiras que, por muitas vezes, evitam outras atividades consideradas administrativas. É possível afirmar que, a dimensão "processo", não é tida como prioridade pelos empresários pelo receio de modificar processos que, de certa forma, já funcionam, e, tendem a apresentar uma resistência à mudanças, estejam atreladas ou não ao uso de sistemas de informação (BASHEIN; MARKUS; RILEY, 1994).

Algumas das ações sugeridas para melhorar essa dimensão, seria a padronização dos processos de produção, desenvolvimento de planejamento, controle de processos produtivos, implantação de ferramentas de qualidade, parceria com outras empresas e fornecedores para enxugar os estoques, realização de inventário de produtos acabados, matéria prima e tratamento de resíduos físicos, como, por exemplo, revenda de refugo para reciclagem.

Em nenhuma das indústrias analisadas havia profissional alocado para desenvolver ou implantar inovações. Além disso, nenhuma atingiu boa pontuação na nota global do diagnóstico, não sendo consideradas inovadoras em seu segmento. Nesse caso, percebe-se uma grande deficiência nos processos destas MPE da região, foco do presente estudo.

\section{CONSIDERAÇÕES FINAIS}

Este artigo teve como principal vertente, identificar oportunidades de melhoria e inovação na dimensão "processos" nas pequenas indústrias entrevistadas. Nota-se que estes negócios têm muito em comum, por exemplo: a maioria iniciou-se como microempresa ou negócio familiar, e, após seu crescimento, obteve aumento de seu faturamento, número de funcionários e etc.

A falta de um bom planejamento estratégico e boas práticas de gestão, alinhadas aos valores e cultura organizacional, contexto que foi abordado na análise dos resultados, limitam muito o potencial de inovação nestas empresas. Sedimentar a gestão da inovação como um processo contínuo depende de bom gerenciamento com funcionários qualificados e motivados a realizarem inovação como meio de estímulo ao desenvolvimento tecnológico e da organização. 


\section{REFERÊNCIAS}

BACHMANN, D. L.; DESTEFANI, J. H. Metodologia para estimar o grau de inovação nas MPE: cultura do empreendedorismo e inovação. Curitiba: Bachmann \& Associados, 2008.

BACHMANN ASSOCIADOS. Metodologia para determinar o radar da inovação nas pequenas empresas. Curitiba: [s.n.], 2011.

BASHEIN, B. J.; MARKUS, M. L.; RILEY, P. Precondition for BPR success and how to prevent failures. Information Systems Management, v.11, n. 2, p.7-13, 1994.

DAVENPORT, T. H. et al. The new industrial engineering: information technology and business process redesign. Sloan Management Review, v. 31, n. 4, 11 p., summer 1990. Disponível em: <http://is.ieis.tue.nl/education/bpmcourse/papers/Davenport\%20(1990)\%20\%20The\%20New\%20Industrial\%20Engineering.pdf>. Acesso em: 01 ago. 2017.

FACÓ, J. F. B.; MANDEL, P. A. Aqui tem inovação!. 1. ed. São Paulo: Editora UFABC, 2016. $168 \mathrm{p}$.

INSTITUTO BRASILEIRO DE GEOGRAFIA E ESTATÍSTICA. Censo Demográfico Brasileiro, 2010. Disponível em: 〈http://www.ibge.gov.br〉. Acesso em: 01 ago. 2017.

JOIA, L. A. Reengenharia e Tecnologia da Informação: o paradigma do camaleão. São Paulo: Pioneira, 1994.

OCDE. Manual de Oslo: Diretrizes para a coleta e interpretação de dados sobre Inovação. GARCHET, P. (trad.). 3. ed. FINEP, 2007.

PORTER, M. E. Strategy and the Internet. Harvard: Harvard Business Review, 2001.

SAWHNEY, M.; WOLCOTT, R. C.; ARRONIZ, I. The 12 different ways for companies to innovate. MIT Sloan Management Review, Cambridge, v. 47, n. 3, 10 p., 2006. Disponível em:

<http://www.cheraghbargh.com/uploads/products/SMR\%20The\%2012\%20Different\%20Way s\%20for\%20companies\%20to\%20Innovate.pdf>. Acesso em: 01 ago. 2017.

SERVIÇO BRASILEIRO DE APOIO ÀS MICRO E PEQUENAS EMPRESAS. Cadernos de Inovação em Pequenos Negócios, Brasília, v. 3, n. 3, 141 p., nov. 2015. Disponível em: <http://www.bibliotecas.sebrae.com.br/chronus/ARQUIVOS_CHRONUS/bds/bds.nsf/f6988a fa855f992333e35bba423fdfe7/\$File/5805.pdf>. Acesso em: 01 ago. 2017.

TURBAN, E.; WETHERBE, J.C.; MCLEAN. E. Tecnologia da Informação para Gestão. Porto Alegre: Bookman, 2004. 